\title{
Berberine Attenuated Oxidative Stress Induced by Sodium Nitrite in
} Rat Liver

\author{
Morteza Akhzari ${ }^{1}$, Sayed Mohammad Shafiee ${ }^{1}$, Sajjad Rashno ${ }^{1}$ and Masoumeh Akmali ${ }^{1,{ }^{*}}$ \\ ${ }^{1}$ Departments of Biochemistry, School of Medicine, Shiraz University of Medical Sciences, Shiraz, Iran \\ "Corresponding author: Department of Biochemistry, Shiraz University of Medical Sciences, P.O. Box: 1167, Shiraz, Iran. Tel: +98-9171809040, Fax: +98-7132303029, Email: \\ akmali34@yahoo.com
}

Received 2018 March 11; Revised 2018 April 30; Accepted 2018 May 29.

\begin{abstract}
Background: Berberine is a well-known alkaloid derived from Berberis species.

Objectives: The present study aimed to investigate the hepatoprotective properties of berberine and elucidate its probable mechanisms against sodium nitrite toxicity.

Methods: Forty animals were randomly classified into five equal groups to be treated for 60 days, including group 1: Control, group 2: Berberine-treated (100 mg/kg), group 3: Sodium nitrite-treated ( $80 \mathrm{mg} / \mathrm{kg}$ ), group 4: Sodium nitrite together with $50 \mathrm{mg} / \mathrm{kg}$ of berberine, and group 5: Sodium nitrite together with $100 \mathrm{mg} / \mathrm{kg}$ of berberine. The protective effects of berberine against sodium nitrite induced-liver damage were investigated using parameters related to oxidative stress, inflammation, fibrosis, and apoptosis in the hepatocytes.

Results: Treatment of rats with sodium nitrite considerably increased alanine aminotransferase (ALT) and alkaline phosphatase (ALP) activities, malondialdehyde (MDA) content, tumor necrosis factor (TNF)- $\alpha$ expression, caspase-3 activity, and transforming growth factor (TGF)- $\beta$ 1 concentration $(\mathrm{P}<0.05)$ and significantly declined the levels of reduced glutathione (GSH), glutathione reductase (GR), glutathione S-transferase (GST), and glutathione peroxidase (GPx) $(\mathrm{P}<0.05)$. The treatment of intoxicated rats with $100 \mathrm{mg} / \mathrm{kg}$ of berberine significantly reversed these changes and reached the values approximately to the normal level. However, berberine $50 \mathrm{mg} / \mathrm{kg}$ failed to normalize the disturbances.

Conclusions: This study demonstrated that berberine could decrease sodium nitrite-induced liver injury in a dose-dependent manner probably due to its antioxidant, anti-inflammatory, anti-apoptotic, and antifibrotic capacities.
\end{abstract}

Keywords: Berberine, Sodium Nitrite, Oxidative Stress, Liver Injury

\section{Background}

Sodium nitrite is a food additive widely used in the food and drug industries as a preservative and fixative for meat and fish. It prevents the growth of Clostridium botulinum spores and flavors the food. Studies have shown that sodium nitrite is poisonous at high doses due to its oxidative properties (1). Oxidative stress due to the longterm exposure to nitrite can cause methemoglobinemia, carcinogenicity, congenital malformations, and endocrine disturbances in humans (2). Oxidative stress in liver cells is considered as one of the most common events leading to the induction and development of many hepatic disorders $(3,4)$. As the liver has a key role in metabolizing and detoxifying many foreign substances, it is exposed to high levels of free radicals and it is more sensitive to oxidative damage than any other organs $(5,6)$. Oxidative stress increases the mitochondrial permeability, leading to the release of pro- apoptotic factors and caspase-3 activation (7-9). During oxidative stress, a variety of cytokines are released from liver tissues such as transforming growth factor(TGF)- $\beta 1$ and tumor necrosis factor (TNF)- $\alpha$; TNF- $\alpha$ as a central player in liver disorders mediates the formation of other cytokines that together damage the hepatocytes. Furthermore, TGF$\beta 1$ is an important mediator in the pathophysiology of the liver, contributing to various liver disease stages. Eventually, oxidative stress enhances inflammation and damage in the hepatic tissue and causes liver dysfunction $(6,10)$. Under normal physiological states, cellular free radicals production is modulated by the action of cellular antioxidant defense such as reduced glutathione (GSH), ascorbic acid, and vitamin $\mathrm{E}$ as non-enzymatic antioxidants, as well as catalase (CAT), superoxide dismutase (SOD), glutathione peroxidase (GPx), and glutathione reductase (GR) as enzymatic antioxidants (9). Novel management methods of treating disorders use natural antioxidants in food. Natu-

Copyright (c) 2019, Jundishapur Journal of Natural Pharmaceutical Products. This is an open-access article distributed under the terms of the Creative Commons Attribution-NonCommercial 4.0 International License (http://creativecommons.org/licenses/by-nc/4.0/) which permits copy and redistribute the material just in noncommercial usages, provided the original work is properly cited. 
ral antioxidants inhibit the adverse effects of toxic agents and reduce tissue damage (11-13). Berberine is a well-known alkaloid derived from Berberis species. Berberine has different properties including anti-diabetic, anti-lipemic, antitumor, and cardioprotective effects. Additionally, berberine has anti-inflammatory and antioxidant capacities (14). Its antioxidant capacity may be related to enhancing the level of enzyme and non-enzyme antioxidants (15). To the best of our knowledge, the effect of berberine on hepatocyte damage induced by sodium nitrite has not been studied.

\section{Objectives}

The present study aimed to evaluate the hepatoprotctive activity of berberine and investigate its possible mechanisms against sodium nitrite hepatotoxicity.

\section{Methods}

\subsection{Chemicals}

Berberine hydrochloride, 1-chloro-2, 4-dinitrobenzene, glutathione reductase (GR), nicotinamide adenine dinucleotide 2-phosphate reduced tetrasodium salt (NADPH), reduced glutathione (GSH), and l-glutathione oxidized (GSSG) were obtained from Sigma-Aldrich chemical company (St. Louis, MO, USA). Sodium nitrite was obtained from Merck chemical company (Germany). Assay kits to determine the activity of caspase- 3 and TGF- $\beta 1$ in rats' liver were obtained from Abcam chemical company (USA). The cDNA synthesis kit was obtained from Fermentase (Germany). Real-Time SYBR Green Master Mix was obtained from Applied Biosystems, USA, and $\beta$-actin and TNF- $\alpha$ primer synthesis was done by Metabion (Germany).

\subsection{Animals}

Forty male Sprague Dawley rats weighing 200 - 250 g were obtained from the Centre of Laboratory Animals of Shiraz University of Medical Sciences. The animals were maintained under suitable conditions of temperature, humidity, and ventilation (continuous circulation of fresh air) with a 12-hour light/dark cycle according to the Guide for the Care and Use of Laboratory Animals (16). The rats were allowed to have easy access to water and food. The animal study was done according to the guidelines of the Ethics Committee of Shiraz University of Medical Sciences, as mentioned in the Grant Number 94 - 7570 from the ViceChancellor for Research Affairs of Shiraz University of Medical Sciences, Shiraz, Iran.

\subsection{Experimental Design}

The rats randomly classified into five equal groups, including: (1) The control group that received normal saline, (2) berberine-treated control group $(100 \mathrm{mg} / \mathrm{kg}$ ) that was administrated orally with $100 \mathrm{mg} / \mathrm{kg}$ berberine hydrochloride, (3) sodium nitrite group that was orally treated with $80 \mathrm{mg} / \mathrm{kg}$ sodium nitrite, (4) berberine (50 mg/kg)-treated group that was administered orally with $50 \mathrm{mg} / \mathrm{kg}$ off berberine followed by $80 \mathrm{mg} / \mathrm{kg}$ of sodium nitrite, and (5) berberine $(100 \mathrm{mg} / \mathrm{kg})$-treated group that was supplemented orally with $100 \mathrm{mg} / \mathrm{kg}$ berberine followed by 80 $\mathrm{mg} / \mathrm{kg}$ of sodium nitrite. All the doses were administrated orally through intragastric tubes for two months.

\subsection{Sample Collection}

At the end of the 60th day, the rats were anesthetized with ketamine $(70 \mathrm{mg} / \mathrm{kg}$ ) at fasting state and blood samples were drawn by cardiac puncture into clotting tubes. The rats' liver was removed immediately and cleaned with ice-cold saline. Then, the blood samples were spun at 1050 $\mathrm{x} g$ at $24^{\circ} \mathrm{C}$ for five minutes to separate the serum that was stored at $-20^{\circ} \mathrm{C}$ until further analysis. A piece of the liver was separated and homogenized in an ice-cold phosphate buffer ( $\mathrm{pH} 8$ ) at a concentration of $10 \%(\mathrm{w} / \mathrm{v})$ using a Wisetis HG-150 homogenizer and centrifuged $(10,000 \mathrm{x} \mathrm{g})$ at $4{ }^{\circ} \mathrm{C}$ for one hour. Then, the clear supernatant, referred to as the liver homogenate, was kept frozen at $-70^{\circ} \mathrm{C}$ for subsequent analysis.

\subsection{Determination of Serum Enzymes Activities}

The activities of alkaline phosphatase (ALP) and alanine aminotransferase (ALT) were measured using standard techniques and suitable commercial kits (Pars Azmoon Co., Iran).

\subsection{Evaluation of Oxidative Stress}

Hepatic malondialdehyde (MDA), as a marker of lipid peroxidation, was analyzed by the measurement of thiobarbituric acid reacting substances (TBARS) based on the colorimetric method (17). Briefly, after the precipitation of proteins in the liver homogenate by trichloroacetic acid, MDA reacted with the thiobarbituric acid to form a colored substance that was analyzed at $532 \mathrm{~nm}$ using 1, 1, 3, 3tetraethoxypropane (TEP) as a standard. The values were reported as $\mathrm{nmol} / \mathrm{g}$ protein.

\subsection{Measurement of Antioxidant Activity}

Hepatic GSH content was measured by Elman's method $(18,19)$. The test is based on the reduction of $5,5^{\prime}$-dithiobis (2-nitrobenzoic acid; DTNB) as a disulfide compound by GSH, which develops yellow colored thionitrobenzoic acid 
(TNB), with maximum absorption at $412 \mathrm{~nm}$. The concentration of GSH was reported as $\mu \mathrm{mol} / \mathrm{g}$ protein.

Hepatic GST activity was measured by the Habig method (20). The reaction was developed by conjugation of GSH with 1-chloro, 2, 4-dinitrobenzene (CDNB). The increase in absorbance was monitored for $2 \mathrm{~min}$ at $340 \mathrm{~nm}$. The results were reported as $\mathrm{U} / \mathrm{g}$ protein.

Hepatic GR was measured by the Racker method (21). The protocol was based on monitoring the oxidation of NADPH linked to GSSG reduction. This oxidation is reflected by a decrease in the absorbance of NADPH at 340 $\mathrm{nm}$. The results were expressed as $\mathrm{U} / \mathrm{g}$ protein using an extinction coefficient of $6.22 \mathrm{mM} / \mathrm{cm}$ for NADPH.

Hepatic GPx was examined spectrophotometrically according to the method proposed by Fecondo and Augusteyn $(22,23)$. This method is based on the indirect measurement of the activity of GPx. Oxidized glutathione (GSSG) generated by the activity of GPx was changed to its reduced form by glutathione reductase using NADPH. The decrease in the absorbance of NADPH for 3 min at $340 \mathrm{~nm}$ showed the activity of GPx that was reported as U/g protein.

\subsection{Measuring TGF- $\beta 1$ Levels}

An indirect ELISA assay was applied to measure TGF- $\beta 1$ levels by using a TGF- $\beta 1$ ELISA kit. According to the manufacturer datasheet, the assay involved two binding processes at TGF- $\beta 1$ specific antibodies and labeled secondary antibody. Rat TGF- $\beta 1$ specific antibodies were incubated with TGF- $\beta 1$ antigen, followed by the incubation with the secondary antibody. In this assay, TGF- $\beta 1$ antigen was located between TGF- $\beta 1$ specific antibodies coated on the plate and an enzyme-labeled, anti-species globulin conjugate. The addition of an enzyme substrate-chromogen reagent (tetramethylbenzidine) caused the color to develop. This color was directly proportional to the quantity of rat TGF- $\beta 1$ antigen capture on the plate. The results were expressed as pg/mg protein.

\subsection{Evaluation of Caspase-3 Activity}

Caspase-3 activity was measured using a commercial kit (Abcam, USA). The assay was based on the colorimetric sensing of the chromophore p-nitroaniline (p-NA) at 400 or $405 \mathrm{~nm}$ after cleavage from the labeled substrate DEVD (Asp-Glu-Val-Asp)-p-NA by caspase-3. The comparison of the absorbance of p-NA from an induced control with an apoptotic sample determined the increased amount of caspase3 activity.

\subsection{RNA Extraction and Quantitative Real-Time PCR (RT-PCR)}

The TNF- $\alpha$ level as a proinflammatory marker was quantified by quantitative real-time PCR (qRT-PCR) method. First, the total tissue RNA was extracted using phenol-chloroform extraction method (24). Concentrations were measured at $260 \mathrm{~nm}$ and RNA samples with the $260 / 280 \mathrm{~nm}$ absorbance ratios of more than 1.6 were chosen. Reverse transcription was done using $1 \mathrm{~g}$ of RNase free DNase-treated total RNA and random primer using Revert Aid First Strand cDNA Synthesis kit (Fermentas, USA). Quantitative real-time PCR was performed using a Real-Time PCR system (Applied Biosystems, USA) with SYBR Green PCR Master Mix according to the manufacturer's instruction. The primer sequences were

$5^{\prime}$ - ACGCTCTTCTGTCTACTG-3' and 5' - CTTGGTGGTTTGCTACGA $-3^{\prime}$ for TNF- $\alpha$ and $5^{\prime}$ - CCACACCCGCCACCAGTTCG- $3^{\prime}$ and $5^{\prime}$-CTAGGGCGGCCCACGATGGA- $3^{\prime}$ for $\beta$-actin. After PCR amplification, all qRT-PCR assays were linear within this concentration range with correlation coefficients $\left(\mathrm{r}^{2}\right)$ of $>$ 0.999. Data were evaluated with the comparative $2^{-\Delta \Delta \mathrm{Ct}}$ method. Relative amounts of TNF- $\alpha$ mRNA were normalized to the levels of $\beta$-actin mRNA for each sample (25).

\subsection{Histopathological Analysis}

The liver was removed and immediately fixed in $10 \%$ formaldehyde for at least 24 hours. Then, the fixed tissues were embedded in paraffin and five-micrometer thickness sections were prepared for staining with hematoxylin and eosin (H\&E). After staining, the extent of the chronic liver injury was assessed by a light microscope.

\subsection{Statistical Analysis}

All data were analyzed using Prism V. 5. Values are presented as means \pm SEM. The Kolmogorov-Smirnov test was used for checking the normality of the data. The statistical difference was calculated using the one-way analysis of variance (ANOVA) test for comparison of five mean values, followed by the Tukey post hoc test for comparison of two mean values. Differences with $\mathrm{P} \leq 0.05$ were determined to be statistically significant.

\section{Results}

\subsection{Effect of Berberine on Serum Enzyme Activities}

The effect of berberine on liver function tests is presented in Figure 1. Serum ALT and ALP activities were significantly elevated by about $58 \%$ and $13 \%(\mathrm{P}<0.05)$, respectively, in sodium nitrite-treated animals, indicating the liver damage. However, the administration of $100 \mathrm{mg} / \mathrm{kg}$ berberine normalized the enzyme levels $(\mathrm{P}>0.05)$ and 50 $\mathrm{mg} / \mathrm{kg}$ berberine could slightly reduce the activities of the enzymes. There were no significant differences in the enzyme levels between the control group and rats administrated with berberine alone $(\mathrm{P}>0.05)$. 

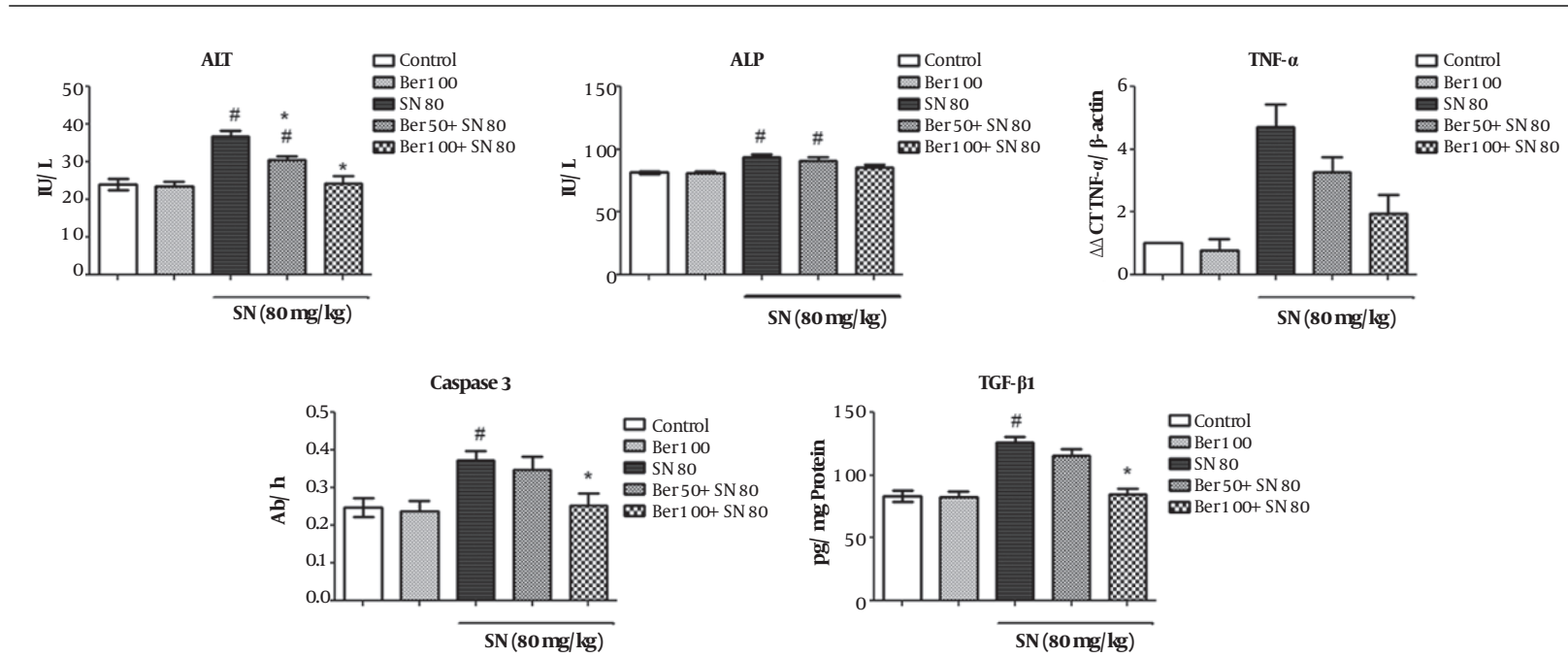

Figure 1. Co-treatment effects of berberine on liver injury biomarkers. Each value represents a mean \pm SEM of eight rats per group. \# Significantly different $(P<0.05)$ from the control group. *Significantly different $(\mathrm{P}<0.05)$ from the positive control group (sodium nitrite group).

\subsection{Effect of Berberine on Oxidative Stress}

As shown in Figure 2, there was a considerable elevation in the MDA level by $46 \%$ in the rats of sodium nitrite group compared to the control group $(\mathrm{P}<0.05)$. Although the treatment with the low dose of berberine $(50 \mathrm{mg} / \mathrm{kg}$ ) failed to completely restraint oxidative stress, the administration of the high dose of berberine $(100 \mathrm{mg} / \mathrm{kg})$ to rats intoxicated with sodium nitrite caused a significant decrease in the MDA content by about $32 \%(\mathrm{P}<0.05)$ compared to the sodium nitrite group. There was no difference in lipid peroxidation levels between the control group and rats administrated with berberine alone $(\mathrm{P}>0.05)$.

\subsection{Effect of Berberine on GSH Redox System}

The effect of berberine on antioxidant activities is presented in Figure 2. As seen, a significant decrease in the GSH content by $18 \%$ and decreases in the GST, GR, and GPX activities in rats of sodium nitrite group were observed compared to the control group $(\mathrm{P}<0.05)$. The highest decrease in the activities of the antioxidant enzymes was observed in GST (28\%), followed by GR and GPx (18\% each). However, the administration of berberine in the sodium nitrite group alleviated the antioxidant enzymes and GSH levels in a concentration-dependent manner. The administration of high-dose berberine $(100 \mathrm{mg} / \mathrm{kg}$ ) to rats intoxicated with sodium nitrite caused a significant increase in the levels of GSH up to $19 \%$, GST up to $34 \%$, and GPx and GR up to $18 \%$ and normalized them compared to the sodium nitrite group. The administration of berberine $(100 \mathrm{mg} / \mathrm{kg})$ alone did not have a noticeable effect on the antioxidant capacity in rats compared to the control group $(\mathrm{P}>0.05)$.

\subsection{Effect of Berberine on Caspase-3 Activity}

While sodium nitrite caused a significant increase (51\%) in hepatic caspase-3 activity $(\mathrm{P}<0.05$ vs. the control group), the administration of $100 \mathrm{mg} / \mathrm{kg}$ of berberine resulted in a significant reduction in the caspase- 3 activity in rats intoxicated with sodium nitrite compared to the sodium nitrite group $(\mathrm{P}<0.05)$. No significant change in the caspase-3 activity was observed in rats treated with 100 $\mathrm{mg} / \mathrm{kg}$ of berberine alone $(\mathrm{P}>0.05)$ (Figure 1$)$.

\subsection{Effect of Berberine on Hepatic TGF - $\beta 1$ Levels}

There was a marked increase in the quantity of TGF- $\beta 1$ by $52 \%$ in the group of rats intoxicated with sodium nitrite ( $\mathrm{P}<0.05$ vs. the control group). However, administration of both doses of berberine (100 and $50 \mathrm{mg} / \mathrm{kg}$ ) to the rats receiving sodium nitrite decreased the TGF- $\beta 1$ levels about $33 \%$ and $10 \%$, respectively, compared to sodium nitrite group. These changes were significant vs. the sodium nitrite group $(\mathrm{P}<0.05)$. Animals treated with berberine $(100 \mathrm{mg} / \mathrm{kg}$ ) alone revealed no major difference in the levels of TGF- $\beta 1$ ( $\mathrm{P}<0.05$ vs. the control group) (Figure 1$)$.

\subsection{Effect of Berberine on TNF- $\alpha$ Expression}

Figure 1 shows an elevation in TNF- $\alpha$ expression, as an important proinflammatory cytokine, in rats treated with sodium nitrite compared with the normal ones ( 4.7 folds) $(\mathrm{P}<0.05)$. Administration $100 \mathrm{mg} / \mathrm{kg}$ of berberine reduced TNF- $\alpha$ expression in the rats intoxicated with sodium nitrite, but it could not completely reach the normal levels. TNF- $\alpha$ expression levels in the rats were 1.9 folds those of normal values, respectively ( $\mathrm{P}>0.05)$. Treatment with 100 

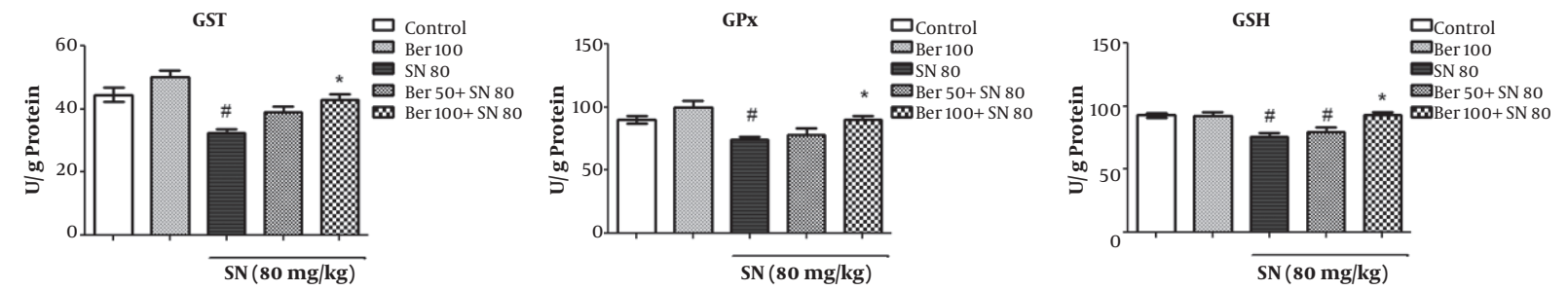

GR
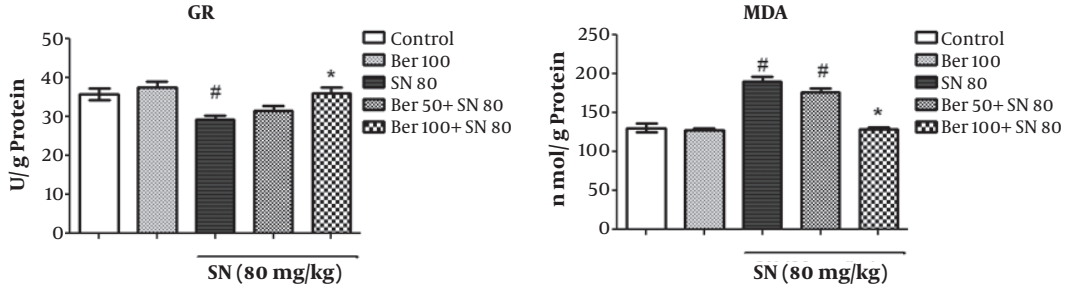

Figure 2. Co-treatment effects of berberine on oxidative stress biomarkers (GST, GPx, GSH, GR, and MDA). Each value represents a mean \pm SEM of eight rats per group. \# Significantly different $(\mathrm{P}<0.05)$ from the control group. * Significantly different $(\mathrm{P}<0.05)$ from the positive control group (sodium nitrite group)

$\mathrm{mg} / \mathrm{kg}$ of berberine did not affect the control group $(\mathrm{P}>$ 0.05).

\subsection{Histopathology}

Hepatic sections from control rats (Figure $3 \mathrm{~A}$ ) exhibited a normal liver structure as the same as in the berberine-treated control group (Figure 3B). Congestion and severe inflammation were observed in rats 60 days after sodium nitrite treatment (Figure 3C). Berberine $50 \mathrm{mg} / \mathrm{kg}$ did not inhibit the toxic effect of sodium nitrite; therefore, abnormalities and histological changes were still present (Figure 3D). However, berberine $100 \mathrm{mg} / \mathrm{kg}$ reduced the hepatic damage (Figure 3E).

\section{Discussion}

Oxidative stress occurs when free radicals accumulate in the cell and the antioxidant system fails to neutralize them. This phenomenon damages the major ingredients of the cell, including lipids, proteins, and nucleic acids located in the cell membrane, cytosol, and nucleus that ultimately leads to cell damage $(19,26)$. The present study showed that chronic exposure to sodium nitrite caused oxidative stress in the liver and berberine treatment could attenuate oxidative damage. Lipid peroxidation is one of the important causes of cell toxicity by sodium nitrite. Nitrite reacts with amines in the stomach generating nitrosamines and free radicals. Nitrosamines can enhance lipid peroxidation, especially in the cell membrane. As normal hepatocytes function depends on the intactness of their membrane, the lipid peroxidation results in membrane disintegrity and cell injury, as reported in previous studies $(27,28)$. In support of these findings, our study indicated a great elevation in serum ALP and ALT activities, as well as hepatocytes MDA, in the sodium nitrite group proposing sodium nitrite-induced lipid peroxidation and impairment of the cell membrane in hepatocytes (29). In addition, sodium nitrite markedly decreased the capacity of the GSH redox system of the hepatocytes possibly due to the high formation of free radicals such as NO. Reports show that NO in high levels can be added to superoxide anions that are usually generated by cell organelles to produce a dangerous free radical, peroxynitrite. NO and peroxynitrite react with active sites on enzymes and inactivate them to disrupt the antioxidant system (30). However, the administration of a high dose of berberine $(100 \mathrm{mg} / \mathrm{kg})$ blocked all of these effects. The improvement of abnormal activities of serum ALP and ALT, as well as liver MDA content, probably is a result of the protection and recovery of liver cells. Besides, berberine treatment showed a positive effect on antioxidant capacity in the liver. Berberine enhanced enzymatic and non-enzymatic antioxidants in the GSH redox system of liver cells. The antioxidative property of berberine is possibly due to its ability in scavenging of free radicals. Studies show that berberine has a strong reductive capacity and radical quenching effect, especially for NO, superoxide anions, and hydroxyl radicals (31). On the other hand, the current study demonstrated that berberine has anti-inflammatory, anti-apoptotic, and antifibrotic properties. Berberine reduced TNF- $\alpha$ expression, TGF- $\beta 1$ concentration, and caspase- 3 activity in rats intoxicated with sodium nitrite. The production of TNF$\alpha$, a major proinflammatory factor, is one of the first processes in many hepatic disorders triggering the formation 

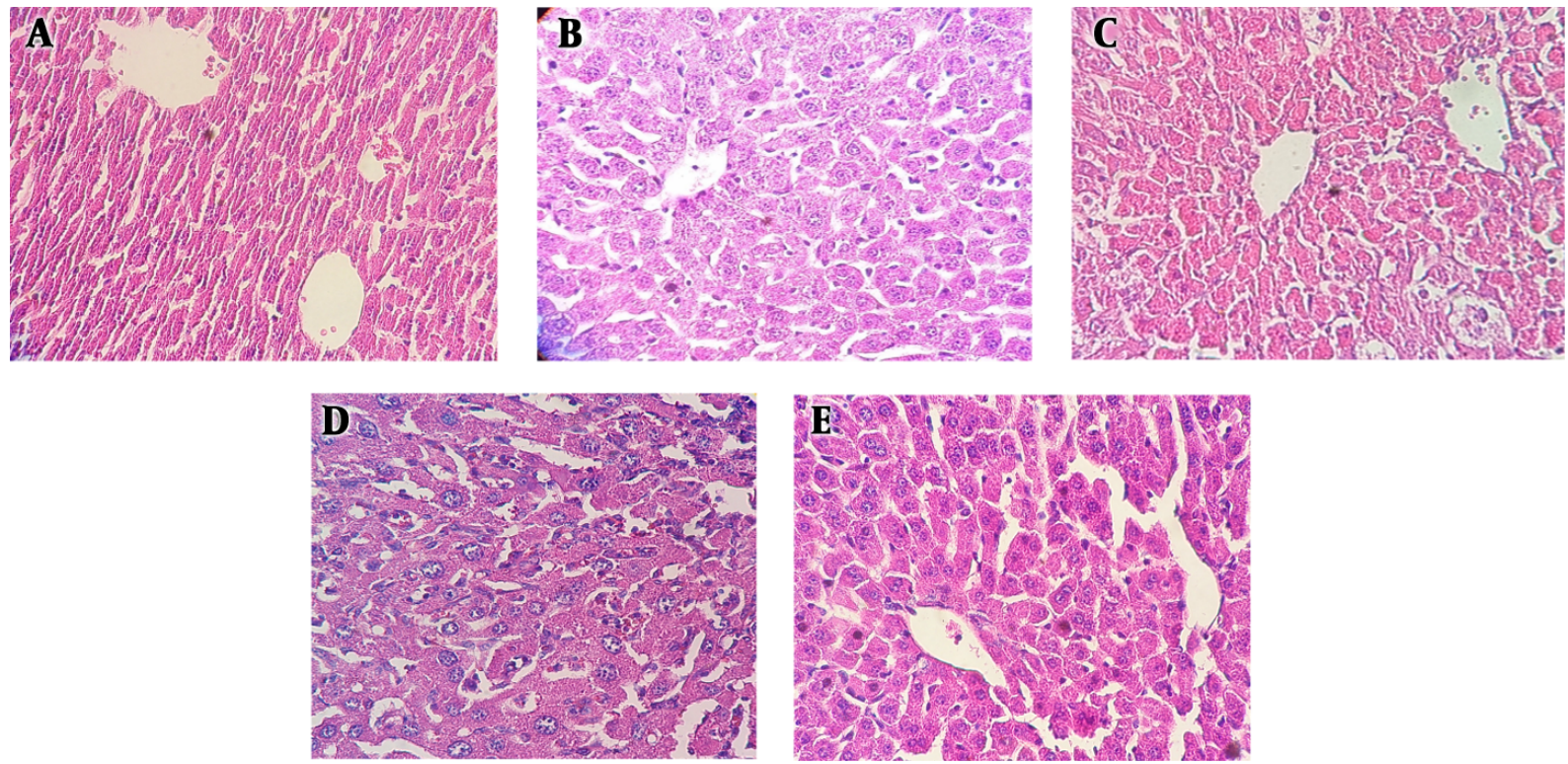

Figure 3. The effect of berberine(A-E) on liver histopathology (hematoxylin and eosin staining) in the liver of sodium nitrite-treated rats. A, the control group showing normal lobular architecture and cell structure; B, the group receiving $100 \mathrm{mg} / \mathrm{kg}$ of berberine alone showing a histological pattern similar to controls; C, sodium nitrite treated-group with hepatic damage including inflammation and congestion; D, the low-dose berberine $(50 \mathrm{mg} / \mathrm{kg})$ treated-group with no noticeable effect on hepatic damage; E, the highdose berberine $(100 \mathrm{mg} / \mathrm{kg})$ treated-group with reduced liver damage. Hepatic lobule shows mild congestion.

of other cytokines. The response of hepatocytes to TNF- $\alpha$ depends on the interaction of TNF- $\alpha$ with other cytokines and modulation of signaling pathways. It means that TNF$\alpha$ can induce cell survival and proliferation, as well as cell damage. The damage to hepatocytes is due to the activation of signaling pathways that causes the elevated mitochondrial production of free radicals and lipid peroxidation, as well as caspase activation $(32,33)$. In our study, sodium nitrite increased the TNF- $\alpha$ expression up to 4.7 folds of normal ones, whereas co-treatment by $100 \mathrm{mg} / \mathrm{kg}$ of berberine and sodium nitrite decreased the TNF- $\alpha$ expression by 1.9 folds of normal ones, showing reduced inflammation. TGF- $\beta 1$ is a chief modulator in the chronic hepatic disease that is effective in all stages of the disease progression from initial liver injury to cirrhosis. Its high levels activate hepatic stellate cells (HSCs) to change them into myofibroblasts that lead to hepatic fibrogenesis (34, 35). In our study, berberine (100 mg/kg) almost normalized the TGF- $\beta 1$ concentration in rats treated with sodium nitrite. This explains the ability of berberine to decrease fibrosis. Caspases, a family of cysteine proteases, are important players in the cell death-mediated apoptosis. However, recent studies indicated that caspases activation is not exactly equivalent to apoptosis and caspases activation always does not result in cell death $(36,37)$. Our results showed that treatment with sodium nitrite caused a considerable increase in caspase-3 activity, which was sup- pressed by berberine (100 $\mathrm{mg} / \mathrm{kg}$ ). Therefore, the mechanisms of the supporting action of berberine against injury stimulated by sodium nitrite can be explained by its antioxidant, anti-inflammatory, anti-apoptotic, and antifibrotic capacities. However, dosage plays an important role in the ameliorative effects of berberine. A dose of 100 $\mathrm{mg} / \mathrm{kg}$ of berberine was more potent than a dose of 50 $\mathrm{mg} / \mathrm{kg}$. Nevertheless, there are still some controversies about the effects of berberine on different experimental models of toxicity. For example, Janbaz and Gilani (38) reported that berberine administration $\left(4 \mathrm{mg} / \mathrm{kg}\right.$ ) after $\mathrm{CCl}_{4-}$ induced liver toxicity showed no effect in reducing liver injury. Li and $\mathrm{Wu}$ (39), however, reported that berberine protected against liver injury in the $\mathrm{CCl}_{4}$ model of hepatotoxicity. This difference between the two studies may be due to dissimilarities in dosage, animal models, and animal species. The current study recommends that the duration of berberine treatment and its applied dose possibly are essential factors. Berberine ( 50 and $100 \mathrm{mg} / \mathrm{kg}$ ) treatment for two months in our work was very different from the dose (4 $\mathrm{mg} / \mathrm{kg}$ ) and duration (two days) in the study by Janbaz and Gilani. In conclusion, our results confirmed that berberine protects hepatocytes against sodium nitrite-induced oxidative injury in a dose-dependent manner, probably due to its antioxidant, antifibrosis, anti-apoptotic, and antiinflammatory properties. 


\section{Footnotes}

Authors' Contribution: Morteza Akhzari and Sayed Mohammad Shafiee participated equally to this work as the co-first authors. Masoumeh Akmali designed the study. Sajjad Rashno and Sayed Mohammad Shafiee help in set up experiment and Morteza Akhzari did the experiment and wrote the manuscript.

Conflict of Interests: The authors have no conflict of interests to disclose.

Ethical Considerations: The animal study was completed according to the guidelines of the Ethics Committee of Shiraz University of Medical Sciences.

Funding/Support: This paper was extracted from a Ph.D. thesis by Morteza Akhzari and was supported by Grant Number 94-7570 from the vice-chancellor for research affairs of Shiraz University of Medical Sciences, Shiraz, Iran.

\section{References}

1. Sindelar JJ, Milkowski AL. Human safety controversies surrounding nitrate and nitrite in the diet. Nitric Oxide. 2012;26(4):259-66. doi: 10.1016/j.niox.2012.03.011. [PubMed: 22487433].

2. National Research Council. Nitrate and nitrite in drinking water. National Academies Press; 1995.

3. Kalantari H, Foruozandeh H, Khodayar MJ, Siahpoosh A, Saki N, Kheradmand P. Antioxidant and hepatoprotective effects of Capparis spinosa L. fractions and Quercetin on tert-butyl hydroperoxideinduced acute liver damage in mice. $J$ Tradit Complement Med. 2018;8(1):120-7. doi: 10.1016/j.jtcme.2017.04.010. [PubMed: 29321999]. [PubMed Central: PMC5755993].

4. Kalantar M, Shirali S, Hasanvand A, Valizadeh M, Tavakoli R, Asadi M, et al. Ameliorative effects of hydroalcoholic extract of lavandula officinalis l. on methotrexate-induced oxidative stress in rats. Pharm Sci. 2017;23(1):18-26. doi:10.15171/PS.2017.04.

5. Zimmerman HJ. Hepatotoxicity: The adverse effects of drugs and other chemicals on the liver. Lippincott Williams \& Wilkins; 1999.

6. Cichoz-Lach $\mathrm{H}$, Michalak A. Oxidative stress as a crucial factor in liver diseases. World J Gastroenterol. 2014;20(25):8082-91. doi: 10.3748/wjg.v20.i25.8082. [PubMed: 25009380]. [PubMed Central: PMC4081679].

7. Kowaltowski AJ, Castilho RF, Vercesi AE. Mitochondrial permeability transition and oxidative stress. FEBS Lett. 2001;495(1-2):12-5. doi: 10.1016/S0014-5793(01)02316-X. [PubMed: 11322939].

8. Yuan J, Murrell GA, Trickett A, Wang MX. Involvement of cytochrome c release and caspase- 3 activation in the oxidative stress-induced apoptosis in human tendon fibroblasts. Biochim Biophys Acta. 2003;1641(1):35-41. doi: 10.1016/S0167-4889(03)00047-8. [PubMed: 12788227].

9. Rahman T, Hosen I, Islam MMT, Shekhar HU. Oxidative stress and human health. Adv Biosci Biotech. 2012;3(7):997. doi: 10.4236/abb.2012.327123.

10. Zhu R, Wang Y, Zhang L, Guo Q. Oxidative stress and liver disease. Hepatol Res. 2012;42(8):741-9. doi: 10.1111/j.1872-034X.2012.00996.x. [PubMed: 22489668].

11. Stickel F, Schuppan D. Herbal medicine in the treatment of liver diseases. Dig Liver Dis. 2007;39(4):293-304. doi:10.1016/j.dld.2006.11.004. [PubMed: 17331820].
12. Goudarzi M, Esmaeilizadeh M, Dolatshahi M, Kalantar H, Frouzandeh $\mathrm{H}$, Kalantar M. Protective effect of elaeagnus angustifolia L. fruit hydroalcoholic extract on cyclophosphamide-induced nephrotoxicity in mice. Shiraz E Med J. 2018;19(1). doi: 10.5812/semj.55075.

13. Kalantari H, Nazari Z, Keliddar A, Foruozandeh H, Kalantar M. Study of the protective effect of livergol against liver toxicity caused by bromobenzene in mice. Iran J Pharm Sci. 2014;10(2):11-20.

14. Mehrzadi S, Fatemi I, Esmaeilizadeh M, Ghaznavi H, Kalantar H, Goudarzi M. Hepatoprotective effect of berberine against methotrexate induced liver toxicity in rats. Biomed Pharmacother. 2018;97:233-9. doi: 10.1016/j.biopha.2017.10.113. [PubMed: 29091871].

15. Preeti S, Prabhat U, Shardendu M, Ananya S, Suresh P. Berberine a potent substance for researcher: A review. World J Pharm Pharm Sci. 2015;4(7):547-73.

16. National Research Council. Guide for the Care and Use of Laboratory Animals. 8th ed. Washington: National Academies Science Press; 2011.

17. Zeb A, Ullah F. A simple spectrophotometric method for the determination of thiobarbituric acid reactive substances in fried fast foods. J Anal Methods Chem. 2016;2016:9412767. doi: 10.1155/2016/9412767. [PubMed: 27123360]. [PubMed Central: PMC4830699].

18. Rahman I, Kode A, Biswas SK. Assay for quantitative determination of glutathione and glutathione disulfide levels using enzymatic recycling method. Nat Protoc. 2006;1(6):3159-65. doi: 10.1038/nprot.2006.378. [PubMed: 17406579].

19. Kalantar H, Kalantar M, Kalantari H, Goudarzi M, Rashidi M. Nephroprotective effect of Gallic acid against mercuric chloride $(\mathrm{HgCl} 2)$ induced damage in rats. Peer-Rev Multidisciplinary Pharm Sci J. 2018;1(1):27. doi:10.22037/ipa.v1i1.20117.

20. Habig WH, Jakoby WB. [27] Glutathione S-transferases (rat and human). Method Enzymol. 77. Elsevier; 1981. p. 218-31. doi: 10.1016/So0766879(81)77029-0.

21. Maheshwari DT, Yogendra Kumar MS, Verma SK, Singh VK, Singh SN. Antioxidant and hepatoprotective activities of phenolic rich fraction of Seabuckthorn (Hippophae rhamnoides L.) leaves. Food Chem Toxicol. 2011;49(9):2422-8. doi: 10.1016/j.fct.2011.06.061. [PubMed: 21723907].

22. Ma L, Liu J, Li N, Wang J, Duan Y, Yan J, et al. Oxidative stress in the brain of mice caused by translocated nanoparticulate $\mathrm{TiO} 2$ delivered to the abdominal cavity. Biomaterials. 2010;31(1):99-105. doi: 10.1016/j.biomaterials.2009.09.028. [PubMed: 19783296].

23. Ghaznavi H, Fatemi I, Kalantari H, Hosseini Tabatabaei SMT, Mehrabani M, Gholamine B, et al. Ameliorative effects of gallic acid on gentamicin-induced nephrotoxicity in rats. J Asian Nat Prod Res.2018;20(12):1182-93. doi:10.1080/10286020.2017.1384819. [PubMed: 28978297].

24. Chomczynski P, Sacchi N. The single-step method of RNA isolation by acid guanidinium thiocyanate-phenol-chloroform extraction: Twenty-something years on. Nat Protoc. 2006;1(2):581-5. doi: 10.1038/nprot.2006.83. [PubMed: 17406285].

25. Livak KJ, Schmittgen TD. Analysis of relative gene expression data using real-time quantitative PCR and the 2(-Delta Delta $\mathrm{C}(\mathrm{T})$ ) Method. Methods. 2001;25(4):402-8. doi: 10.1006/meth.2001.1262. [PubMed: 11846609].

26. Pham-Huy LA, He H, Pham-Huy C. Free radicals, antioxidants in disease and health. Int J Biomed Sci. 2008;4(2):89-96. [PubMed: 23675073]. [PubMed Central: PMC3614697].

27. Mittal G, Brar AP, Soni G. Impact of hypercholesterolemia on toxicity of N-nitrosodiethylamine: Biochemical and histopathological effects. Pharmacol Rep. 2006;58(3):413-9. [PubMed:16845216].

28. Jacobson K, Witt-Sullivan HB. Interpreting Abnormalities in Routine Liver Biochemistry: How to identify patterns in test results. Can Family Physician. 1992;38:561-6. [PubMed Central: PMC2146029].

29. Zavodnik IB, Lapshina EA, Rekawiecka K, Zavodnik LB, Bartosz G, Bryszewska M. Membrane effects of nitrite-induced oxidation of human red blood cells. Biochim Biophys Acta. 1999;1421(2):306-16. doi: 10.1016/S0005-2736(99)00136-4. [PubMed: 10518700]. 
30. Pacher P, Beckman JS, Liaudet L. Nitric oxide and peroxynitrite in health and disease. Physiol Rev. 2007;87(1):315-424. doi: 10.1152/physrev.00029.2006. [PubMed:17237348]. [PubMed Central: PMC2248324].

31. Luo A, Fan Y. Antioxidant activities of berberine hydrochloride. J Med Plants Res. 2011;5(16):3702-7.

32. Tilg H, Diehl AM. Cytokines in alcoholic and nonalcoholic steatohepatitis. $N$ Engl J Med. 2000;343(20):1467-76. doi: 10.1056/NEJM200011163432007. [PubMed: 11078773].

33. Kalantari H, Rezaei M, Mahdavinia M, Kalantar M, Amanpour Z, Varnaseri G. Determination of the mutagenicity potential of supermint herbal medicine by single cell gel electrophoresis in rat hepatocytes. Adv Pharm Bull. 2012;2(2):245-8. doi: 10.5681/apb.2012.037. [PubMed: 24312800]. [PubMed Central: PMC3845994].

34. Dooley S, ten Dijke P. TGF-beta in progression of liver disease. Cell Tissue Res. 2012;347(1):245-56. doi: 10.1007/s00441-011-1246-y. [PubMed: 22006249]. [PubMed Central: PMC3250614].
35. Liu T, Wang X, Karsdal MA, Leeming DJ, Genovese F. Molecular serum markers of liver fibrosis. Biomark Insights. 2012;7:10517. doi: 10.4137/BMI.S10009. [PubMed: 22872786]. [PubMed Central: PMC3412619].

36. Grütter MG. Caspases: Key players in programmed cell death. Current Opinion Structural Biol. 2000;10(6):649-55. doi: 10.1016/S0959440X(00)00146-9.

37. Abraham MC, Shaham S. Death without caspases, caspases without death. Trends Cell Biol. 2004;14(4):184-93. doi: 10.1016/j.tcb.2004.03.002. [PubMed: 15066636].

38. Janbaz $\mathrm{KH}$, Gilani AH. Studies on preventive and curative effects of berberine on chemical-induced hepatotoxicity in rodents. Fitoterapia. 2000;71(1):25-33. doi: 10.1016/S0367-326X(99)00098-2. [PubMed: 11449466].

39. Li DQ, Wu MJ. Protective effect of berberine on CCl4 induced acute liver injury in mice. China Pharm. 2009;20(21):1618-9. 